\section{International Scientific Journal Theoretical \& Applied Science}

\author{
p-ISSN: 2308-4944 (print) $\quad$ e-ISSN: 2409-0085 (online) \\ Year: $2015 \quad$ Issue: 04 Volume: 24
}

Published: $30.04 .2015 \quad$ http://T-Science.org

\section{Svetlana Valeryevna Fedorova}

Candidate of Technical Sciences, associate professor,

Irkutsk National Research Technical University, Russia

fsta@istu.edu

SECTION 12. Geology. Anthropology. Archeology.

\title{
GLASS AS COMPONENT OF COMPOSITE MATERIALA-MIKALEKS
}

Abstract: From a large number of the composite materials created in recent years the special place is taken by composites on the basis of mica and the glasses combining high dielectric properties with a chemical, thermal and mechanical durability.

Key words: Glass, micalex, composite material, thermal and mechanical durability.

Language: Russian

Citation: Fedorova SV (2015) GLASS AS COMPONENT OF COMPOSITE MATERIALA-MIKALEKS. ISJ Theoretical \& Applied Science 04 (24): 225-229.

Soi: http://s-o-i.org/1.1/TAS*04(24)40 Doi: crossef http://dx.doi.org/10.15863/TAS.2015.04.24.40

\section{СТЕКЛО, КАК СОСТАВНАЯ ЧАСТЬ КОМПОЗИТНОГО МАТЕРИАЛА-МИКАЛЕКС}

Аннотация: Из большого числа композиционных материалов, созданных за последние годы, особое место занимают композиты на основе слюды и стекла, сочетающие в себе высокие диэлектрические свойства с химической, термической и механической прочностью.

Ключевые слова: Стекло, микалекс, композиционный матриал, термическая и механическая прочность.

В качестве связующего в микалексе используется специальное легкоплавкое стекло. Такое стекло должно хорошо смачивать слюду и взаимодействовать с ней при температуре намного ниже температуры деструкции слюды. Оно должно обеспечивать монолитную композицию, способную оказывать сопротивление влиянию химических реагентов, воды, агрессивных сред, иметь высокие электрические характеристики, при нагревании образовывать расплав, способный во время прессования склеивать композит.

Впервые микалекс в нашей стране стал применяться около 50 лет назад. Разработка стекла проводилась в ЛТИ (Ленинградском технологическом институте). Первоначально для производства микалекса применялось борносвинцовое стекло, от которого пришлось отказаться вследствие вредности оксида свинца, дефицитного сырья и большого удельного веса изделия [1,c. 37]. Разработка безсвинцового стекла началась с изучения борно-цинковых стекол состава: $\mathrm{B}_{2} \mathrm{O}_{3}-40$ - 80\%, $\mathrm{ZnO}-20$ - $60 \%$.

Исследование этих стекол показало, что температура размягчения их выше, чем у борносвинцового стекла. Температуру размягчения стекла удалось снизить введением в состав щелочных оксидов. Получили стекло следующего состава:

$$
\mathrm{B}_{2} \mathrm{O}_{3}-55,0 ; \mathrm{BaO}-20,0 ; \mathrm{Na}_{2} 0-25 \quad \text { [2, c.77]. }
$$

На основе этого стекла, образцы микалекса получились удовлетворительного качества, но это стекло имело слишком короткий температурный интервал размягчения и с повышением температуры растворяло слюду поэтому микалекс получается, как бы литой, с недостаточной механической прочностью. При нагреве же слюда не оплавляется стеклом, и микалекс получается пористым. Для изменения состава стекла в него ввели кремнезем:

$\mathrm{SiO}_{2}-17,0 ; \mathrm{B}_{2} \mathrm{O}_{3}-55,0 ; \mathrm{BaO}-5 \% ; \mathrm{Na}_{2} \mathrm{O}-23$ [2,c. 89].

В результате исследования микалекса, изготовленного на основе стекла приведенного состава, было показано, что борно-свинцовое стекло может быть заменено безсвинцовым. Путем систематических изменений состава было получено стекло № 20, которое применялось для производства микалексав 1939-1940гг. [3, c.144]. Были проведены исследования по определению электрических и механических характеристик стекла 203. 
Электрические и механические характеристики стекла 203.

\begin{tabular}{|c|c|}
\hline Наименование параметров & Величина \\
\hline Прочность на сжатие, МПа & $600-2000$ \\
\hline Прочность на разрыв, МПа & $30-100$ \\
\hline Твердость по шкале Мооса & $4-7$ \\
\hline Температура размягчения, ${ }^{\circ} \mathrm{C}$ & $500-720$ \\
\hline Температурный коэфф. расширения, ${ }^{\circ} \mathrm{C}-{ }^{1}$ & $0,5-140-10-^{7}$ \\
\hline Теплопроводность, Вт/м град & $0,7-1,3$ \\
\hline Удельная теплоемкость, КДж/кг град & $0,33-1,05$ \\
\hline Удельное объемное сопротивление, Ом м & $10^{8}-10^{18}$ \\
\hline Диэлектрическая проницаемость & $3,7-16,5$ \\
\hline Тангенс угла диэлектрических потерь при 1 МГц & $0,00012-0,007$ \\
\hline Электрическая прочность, МВ/м & $3,0-4,6$ \\
\hline
\end{tabular}

Учитывая дефицит $\mathrm{B}_{2} \mathrm{O}_{3}$, были проведены работы с целью снижения этого компонента в составе микалекса, в результате чего было получено стекло № 15

Однако это стекло не было принято к использованию в связи с содержанием в его составе соединений фосфора, вредных для человека. Далее для повышения нагревостойкости микалекса сотрудниками ГИС г.Москва были разработаны новые марки стекла [3,с.28]. Были проведены исследования по смачиванию слюды этими стеклами и получены следующие заключения: стекла 2,12,14 начинают смачивать слюду на пределе ее термостойкости или за ее верхним пределом, и поэтому они не пригодны в качестве стеклосвязки. Начало смачивания стеклом [4,c.44] наступает при температуре намного ниже температуры вышеперечисленных стекол [4,c.79]. Промышленное опробование показало, что при температуре горячего прессования $470 \mathrm{C}$ из стекла 15 можно получить хорошо прессованные монолитные пластины микалекса. Стекло 15 выгодно отличается от стекла 203 тем, что в его составе нет вредных примесей, как фтор, и дефицитных, как $\mathrm{BaO}$. Из проводимых исследований свойств микалекса [5,c.112] следует, что высокие диэлектрические и механические параметры композиции со стеклом 15 показали его преимущество по сравнению со стеклом 203 [6, с.202]. Однако использование микалекса на основе 15 стекла 15 в качестве электроизоляционного материала ограничено изза недостаточных электроизоляционных свойств, особенно при повышенных температурах [7, с. 123].

\section{Особенности процесса самоизмельчения стекла.}

Оптимальными размерами частиц, до которых необходимо измельчить стекло, применяемое в качестве связующего при изготовлении композиции слюда - стекло, является класс крупности $-0,2+0,1$.

Эффективность помола для различных материалов можно оценить универсальным критерием - расходом энергии на образование единицы удельной поверхности. Соотношение между ростом удельной поверхности и расходом электроэнергии в значительной мере зависит от свойств материала, способа измельчения, измельчаемого аппарата, времени измельчения и т.д. Характерно, что рост потребляемой энергии всегда опережает увеличение удельной поверхности. Шаровое измельчение малопригодно для тонкого измельчения стекла. Измельченное в шаровых мельницах стекло содержит значительное количество переизмельченного материала. Трудность использования шаровых или стержневых мельниц также состоит и в том, что твердость доступных конструктивных сталей для изготовления мелющих тел и футеровки, как правило, ниже твердости измельчаемого стекла. Кроме того, данный материал обладает еще и абразивными свойствами. Таким образом, помол стекла в мельницах такого типа вряд ли оправдан. Широкое применение в последнее время находят мельницы самоизмельчения. Их использование позволяет практически на порядок повысить производительность с приемлемыми энергетическими затратами.

Во многих отраслях народного хозяйства, там, где необходим тонкий и сверхтонкий класс крупности помола менее 10 мкм, находят применение струйные мельницы. В настоящее время отечественной промышленностью освоен выпуск установок струйного измельчения, применяемых для измельчения антрацита, угля, 
кокса, известняка, кварца и другого минерального сырья, до крупности 60 - 70 мкм. В качестве энергоносителя используется перегретый пар, сжатый воздух, парогазовоздушная смесь. Установки струйного измельчения работают по принципу самоизмельчения при соударении частиц материалов в помольной камере, движущихся в потоках энергоносителя навстречу друг другу. Установки включают питатель, делитель, инжекторные камеры с разгонными трубками. Измельченный материал разделяется в классификаторе, из которого материал необходимой дисперсности отсасывается в систему улавливания пыли, а более крупные частицы возвращаются на доизмельчение. Разряжение создается центробежным вентилятором. Наибольший интерес представляет противоточная струйная мельница.

При измельчении стекла в струйной мельнице основной задачей является установление взаимосвязи между дисперсностью измельчаемого материала и затратами энергии мельницей с заданными конструктивными параметрами. Кинетика измельчения определяется существенным и одновременным влиянием сразу многих факторов, таких, как пластическое и упругое деформирование, взаимодействие частиц между собой и окружающей средой, масштабными изменениями прочности, конструктивными особенностями измельчителя. Этими особенностями процесса обусловлена сложность задачи теории измельчения, которая до настоящего времени не решена полностью. Известные из литературных данных соотношения Риттингера, Кика, Бонда и многие другие основаны на одностороннем учете какоголибо одного из указанных параметров, и поэтому оказались весьма ограниченно притесняемыми для описания экспериментальных данных. Поэтому есть необходимость рассмотрения теории измельчения стекла, в струйной мельнице, посредством математической модели. А именно связанной с затратой энергии по времени поэтому весьма ограничено применяемыми для описания экспериментальных данных. Поэтому есть необходимость рассмотрения теории измельчения стекла в струйной мельнице, посредством математической модели. А именно, связанной с затратой энергии по времени на предельные упругие и пластические деформации стекла с целью получения материала данного класса крупности.

\section{Смачивание твердых поверхностей расплавами стекол.}

При исследовании смачивания твердых поверхностей расплавами стекол определяют краевой угол и условия растекания капли. Необходимость использования этих показателей диктуется практическими потребностями, к числу которых следует отнести получение слоя расплава определенной толщины композиции слюда - стекло.

Теория процесса смачивания поверхности стеклами разработана недостаточно полно. Исключение составляет работа [6.c,67] , в которой изучалось смачивание предварительно загрунтованной стальной поверхности расплавом натрий боросиликатного стекла с добавками двуокиси титана при температуре $850^{\circ} \mathrm{C}$. Стекла такого состава известны под названием титановых эмалей. Смачивание поверхностей натрий титан боросиликатными стеклами с добавками оксидов металлов второй группы периодической системы имеет ряд особенностей. Смачивание различных поверхностей этими стеклами можно связать с процессом образования кристаллов и расплавов стекол. Стекла с добавками оксидов по их способности кристаллизоваться можно расположить в следующий ряд: $\mathrm{BeO}>\mathrm{ZnO}$ $>\mathrm{MgO}>\mathrm{CdO}>\mathrm{CaO}>\mathrm{SrO}>\mathrm{BaO}$. Такие оксиды, как $\mathrm{BeO}, \mathrm{ZnO}, \mathrm{MgO}$, вызывают объемную кристаллизацию стекол. С ростом их содержания число образующихся кристаллов растет, размер их увеличивается, а смачивание ухудшается. Добавки таких кристаллов, как $\mathrm{CaO}, \mathrm{SrO}, \mathrm{BaO}$ и $\mathrm{CdO}, \quad$ способствуют поверхностной кристаллизации, которая, в свою очередь, увеличивает смачивание. Также проводились исследования по смачиванию расплавами стекол кислых и основных оксидов. Кислые - оксиды кремнезем, двуокись титана, окись железа и окись хрома смачиваются лучше, чем основные окись кальция, глинозем. Краевой угол расплава стекол зависит от свойств контактирующих пар [7.c, 69], температуры окружающей среды [8.c,79]. Окислительная среда, как правило, способствует лучшему смачиванию. Смачивание твердых поверхностей расплавами стекол зависит от температуры. Краевой угол при повышении температуры расплава снижается

Начальная температура расплава для более тугоплавких стекол равна $820^{\circ} \mathrm{C}$, а краевой угол составляет $155^{\circ}$ независимо от свойств подложки. Краевой угол можно определять методом замораживания капли, для чего производят резкое охлаждение капли на твердой поверхности. Расхождение в значениях краевого угла, определяемого различными методами не столько различно. Для этой системы, как и в предыдущем случае, смачивание растет с ростом температуры расплава стекол. 
Для равномерного смачивания и распределения расплава стекла по поверхности необходимо учитывать гистерезис краевого угла. Наступающий краевой угол $\mathrm{Q}_{\mathrm{A}}$ определяет растекание расплава, a отступающий QR стягивание слоя расплава в каплю.

Разность между этими углами (QA-QR) обусловливает гистерезис смачивания. В результате гистерезиса возможно собирание расплава в каплю, что в композиции слюдастекло является нежелательным явлением. Гистерезис краевого угла может быть вызван вязкостью расплава, шероховатостью подложки и химической реакцией между контактирующими партнерами. Причины гистерезиса изучались при смачивании железа силикатными расплавами. Часть расплава, содержащая 16\% Na2O и $64 \%$ $\mathrm{SiO} 2$. оставалась неизменной, остальная часть, т.е. $20 \%$, состояла из добавок различных оксидов металлов. При температуре $1200^{\circ} \mathrm{C}$ краевые углы, в зависимости от добавок оксидов других металлов, принимают следующие значения [8.c, 47].

Таблица 2

Значение краевого угла, в зависимости от свойств вводимых оксидов.

\begin{tabular}{|c|c|c|c|c|}
\hline Оксиды металлов & $\mathrm{BaO}$ & $\mathrm{SrO}$ & $\mathrm{CaO}$ & $\mathrm{MgO}$ \\
\hline Краевой угол, градусы: & & & & \\
\hline наступающий & 34 & 48 & 52 & 65 \\
\hline отступающий & 31 & 41 & 40 & 47 \\
\hline Вязкость расплава (lgn), П & 2,02 & 2,12 & 2,15 & 2,56 \\
\hline
\end{tabular}

Гистерезис более значителен у расплава с добавками, вязкость которого превышает вязкость других расплавов. Значение краевого угла, в зависимости от свойств вводимых оксидов, уменьшается в последовательности: $\mathrm{MgO}, \mathrm{CaO}, \mathrm{SrO}, \mathrm{BaO}$.
Эта последовательность соответствует увеличению радиуса катиона металла оксида. Для того, чтобы исключить влияние вязкости на смачивание исследовали растекание капель сплавов, имеющих одинаковую вязкость, равную 1000 П. В этих условиях значения краевого угла характеризуется следующими данными:

Таблица 3

Значение краевого угла, при исключении влияния вязкости на смачивание.

\begin{tabular}{|c|c|c|c|c|c|c|}
\hline Оксиды & $\mathrm{MgO}$ & $\mathrm{ZnO}$ & $\mathrm{TiO}_{2}$ & $\mathrm{MnO}$ & $\mathrm{FeO}$ & $\mathrm{B}_{2} \mathrm{O}_{3}$ \\
\hline Температура, ${ }^{0} \mathrm{C}$ & 1157 & 1100 & 1080 & 1060 & 1125 & 1030 \\
\hline Краевой угол, градусы & & & & & & \\
\hline наступающий & 62 & 37 & 45 & 70 & 21 & 59 \\
\hline отступающий & 39 & 30 & 29 & 16 & 21 & 59 \\
\hline
\end{tabular}

Только у оксида железа, добавление которого улучшает смачивание, не обнаружены гистерезисные явления. Для остальных добавок гистерезис имеет место. Это означает, что причиной гистерезиса является не только вязкость расплава. Кроме гистерезиса, происходит изменение краевого угла с течением времени [9.c,48]. В работе изучалась кинетика смачивания расплавами стекол металлических и высокотемпературных керамических поверхностей. Изменения краевого угла и времени зависит от положения капли на горизонтальной поверхности: она может либо лежать, либо висеть на ней. Для лежащей капли краевой угол с течением времени уменьшается. Для висячей капли под действием гравитационной силы происходит увеличение краевого угла с течением времени контакта. Причем равновесное значение краевых углов, независимо от положения капли, с течением времени примерно одинаково. Чем выше температура, тем быстрее достигается равновесное значение краевых углов в связи с уменьшением вязкости расплава.

Помимо значений краевого угла кинетику смачивания можно оценить по площади контакта капли с поверхностью. Силикаты, содержащие свинец, плохо смачивают твердую молибденовую поверхность и реализуют минимальную площадь контакта. Присутствие в расплавах таких оксидов, как $\mathrm{TiO}_{2}$ и $\mathrm{B}_{2} \mathrm{O}_{3}$, увеличивает смачивание, но не столь существенно, по сравнению с их совместным присутствием в 
расплаве. В последнем случае имеет место максимальная площадь контакта капли.

Таким образом, смачивание поверхностей расплавами стекол зависит от природы смачиваемой поверхности, температуры расплава и наличия различных добавок, в том числе оксидов.

На основании проведенного анализа современного состояния развития исследований в области изготовления слюдокерамических электронагревателей и изучения их свойств, можно сделать следующие выводы:

1. Жаростойкий микалекс обладает высокими термомеханическими свойствами за счет тугоплавкого стекла с температурой размягчения $700^{\circ} \mathrm{C}$, но из-за пористости, которая приводит к большому водопоглощению, не может быть использован как оболочка СКЭНа, поэтому необходимо разработать новый состав стекла с пониженной температурой размягчения, который бы обеспечил более плотную структуру микалексу.

2. Новомикалекс, полученный на основе синтетической слюды фтор флогопит, позволяет использовать стекла, имеющие температуру растекания $800-900^{\circ} \mathrm{C}$, но из-за высокой себестоимости слюды неприемлем в промышленных масштабах, экономически целесообразнее использовать мелкоразмерную, обогащенную, некондиционную слюду мусковит.

3. Композиция на стекле 15 не содержит в своем составе дефицитного компонента, такого, как цинковые белила, кроме того, имеет высокие диэлектрические и механические параметры. Однако использование микалекса на основе стекла $15 \quad$ в электроизоляционного материала ограничено изза недостаточных электроизоляционных свойств. При повышенных температурах рациональнее разработать композицию с высокими электроизоляционными характеристиками при высоких температурах.

\section{References:}

1. (1965) A.s. 175486 SSSR, NKI 12 S 2 Sposob poluchenija kristallov sin teticheskoj sljudy / I.N.Anikin E.E. Kochetkova, SSSR.- № 374904/26-25.- Zajavleno 6.01.64; Opubl.9.10.65.- Bjul.- №20.

2. Lejzerzon MS, Feofilova OP (1960) Novomikaleksy i mikoplastik. Voprosy radiojelektroniki: Ser. IV, 1960. -Vyp. 5, - pp. 28-43.

3. Anikin IN, Kishko VA, Matveev SI (1967) Isskustvennaja sljuda. Tehn. inf. CNIITJe Stroit. Ser. Promyshlennoe proizvodstvo nerudnyh i nemetallorud. materialov. - L., 1967. -Vyp. 3. - pp. 21-23.

4. Kolganova VA, Asnovich JZ, Zabyrina KI (1974) Jelektroizoljacionnye materialy na osnove sljudy ftorflogopit. Jelektrotehnicheskaja promyshlennost'. Ser. Jelektrotehnicheskie materialy. - I., 1974. - Vyp 2. 52. -pp. 2-5.

5. Veksler AS, Ozhigov VN, Mecik MS (1983) Issledovanie termostojkosti kristallov sljudy. Issledovanija $\mathrm{v}$ oblasti fiziki tverdogo tela.I.:Vost-Sib.kn. izd-vo, 1983.-Vyp.1. -pp. 164168.
6. Mecik MS (1988) Termicheskie svojstva kristallov sljudy. -I.:Izd-vo Irkun-ta, 1988. -pp. 184.

7. Tjurin NG, Shishelova TI, Leonova NV, Obuhova AG (1985) Kojefficient diffuzii vody pri degidroksilacii flogopita. VINITI. -Irkutsk, 1985. -pp.2-7.

8. Shishelova TI, Leonova NV, Novgorodceva TI (1990) Ispol'zovanie prirodnogo ftorflogopita dlja izgotovlenija nagrevostojkih bumag. Izv. VUZov. Neorganicheskie materialy, 1990, №5.pp.1117-1119.

9. Kuznecova GA, Krinari GA, Liopo VA (1989) Osobennosti kristal $\neg$ licheskogo fazovogo sostava prirodnyh flogopitov. VINITI. -Irkutsk, 1989. -pp. 30.

10. Liopo VA, Mecik MS, Kuznecova GA, Vojna VV, Kovalevskaja TI, Kalihman VM (1990) Strukturnye izmenenija $\mathrm{v}$ kristallah sljud pri lazernom obluchenii. Izvestija vuzov. Fizika. Tomsk, 1990.- pp.21.

11. (1936) A.s. 47728 SSSR. Sposob izgotovlenija mikaleksa / N.I.Demidov /.-Opubl.31.07.36; MKL2N01V 19/00.

12. (1937) A.s. 50549 SSSR. Sposob izgotovlenija mikaleksa / N. P. Bogorodickij, N.D.Fridberg.Opubl.28.02.37 MKL2 NOJV, 19/00. 